\title{
TEOLOGIA DECOLONIAL E EPISTEMOLOGIAS DO SUL
}

\author{
DECOLONIAL THEOLOGY AND EPISTEMOLOGIES OF THE SOUTH
}

\section{Carlos Alberto Motta Cunha *}

\begin{abstract}
RESUMO
A teologia não é um saber autônomo. Na busca por contextualização e pertinência, a teologia cristã se lança ao diálogo fecundo com outras áreas do conhecimento. Ao ser interpelada pelas demandas de outros saberes, a intelecção da fé se vê obrigada a repensar as suas próprias categorias com o objetivo de manter pública a sua tarefa. A teologia da libertação, por exemplo, chama esse exercício de abertura de mediação sócio-analítica (MSA), isto é, mediação necessária a uma teologia disposta a ouvir a sociedade com finalidades transformadoras e libertadoras. A MSA nos faz aceder ao texto social e discernir a situação de opressão/colonização que afetam o marginalizado ou subalternizado, que é o interlocutor e o destinatário principal não só da teologia da libertação, mas também da teologia decolonial. Desse modo, buscamos resgatar os principais eixos do pensamento decolonial por meio do Grupo Modernidade/Colonialidade/Decolonialidade (Grupo M/C/D) para, no segundo momento, oferecer algumas contribuições para uma teologia decolonial disposta a avaliar o seu próprio referencial teórico/prático a partir dos lugares fronteiriços cujas epistemologias do Sul emergem abrindo espaços para novos ambientes de enunciação da fé cristã.

Palavras-chaves: Decolonialidade. Teologia decolonial. Epistemologias do Sul. Teologia de fronteira.
\end{abstract}

\begin{abstract}
Theology is not an autonomous knowledge. To ensure contextualization and relevance, Christian theology establishes a fruitful dialogue with other areas of knowledge. Challenged by the demands of other knowledges, the intellection of faith is forced to rethink its own categories for its task to remain public. The Theology of Liberation, for example, calls this exercise of opening itself socio-analytic mediation (MSA), that is, a necessary mediation for a theology seeking to listen to the society's transformative and liberating goals. MSA makes us reach the social fabric and discern the situation of oppression/colonization that affects the marginalized or subaltern, who are the interlocutors and the main recipients of both Theology of Liberation and Decolonial Theology. In this study, we seek to explore, together with the Modernity/Coloniality/Decoloniality Group $(M / C / D)$, the main axes of decolonial thought. Then, our aim will be to offer some contributions to a Decolonial Theology willing to assess its own theoretical/practical references, based on a boundary perspective and especially on the epistemologies of the South that emerge, creating new environments for the enunciation of Christian faith.
\end{abstract}

Keywords: Decoloniality. Decolonial Theology. Epistemologies of the South. Border Theology.

* Doutor e pós-doutor em Teologia Sistemática. Atualmente, professor colaborador no Programa de Pósgraduação em Teologia da Faculdade Jesuíta de Filosofia e Teologia (FAJE) e pesquisador do Grupo Fé e Contemporaneidade do CNPq. E-mail: carlosamc04@gmail.com 


\section{INTRODUÇÃO}

A teologia não é um saber autônomo. Na busca por contextualização e pertinência, a teologia cristã se lança ao diálogo fecundo com outras áreas do conhecimento. Ao ser interpelada pelas demandas de outros saberes, a intelecção da fé se vê obrigada a repensar as suas próprias categorias com o objetivo de manter pública a sua tarefa. A teologia da libertação, por exemplo, chama esse exercício de abertura de mediação sócio-analítica (MSA), isto é, mediação necessária a uma teologia disposta a ouvir a sociedade com finalidades transformadoras e libertadoras. A MSA nos faz aceder ao texto social e discernir a situação de opressão/colonização que afetam o marginalizado ou subalternizado, que é o interlocutor e o destinatário principal não só da teologia da libertação, mas também da teologia decolonial.

Neste artigo, propomos um diálogo entre a teologia cristã e o pensamento decolonial. Delimitamos o encontro entre essas duas áreas no contexto da epistemologia. De um lado, as reflexões decoloniais sugeridas pelo grupo de estudos formado por intelectuais latino-americanos e americanistas chamado Grupo Modernidade/Colonialidade/Decolonialidade (Grupo M/C/D) e, do outro lado, uma teologia disposta a repensar a sua essência e a sua tarefa levando em consideração o mundo epistemologicamente diverso. Este "uni-verso" (sugere uma unidade a partir do diverso) oferece à teologia novos lugares de enunciação da fé por meio de sujeitos subalternizados.

O texto está marcado por dois momentos. No primeiro, resgatamos, em linhas gerais, o viés decolonial elaborado pelo Grupo M/C/D. Diferenciamos os termos "descolonial" de "decolonial" para deixar clara a proposta de subversão do "pensamento decolonial" refletido pelo Grupo e, em seguida, apresentamos os principais eixos da teoria: colonialidade do poder, do ser e do saber, o pensamento liminar ou pensamento fronteiriço e o giro decolonial. Já no segundo momento, interpelamos a teologia com o pensamento decolonial. O resultado é uma teologia disposta a se libertar das amarras hegemônicas e colonizadoras; a fazer da fronteira um espaço favorável à desobediência epistêmica e uma teologia que encontra nas “epistemologias do Sul” novos sujeitos e novos lugares de enunciação da fé. 


\section{PENSAMENTO DECOLONIAL}

Decolonial ou descolonial? Uma primeira distinção se faz necessária no modo como vamos abordar o tema da decolonialidade. A distinção entre os dois termos não é somente uma questão de preferência semântica, mas é, fundamentalmente, "provocar um posicionamento - uma postura e atitude contínua - de transgredir, intervir, insurgir e incidir" (WALSH, 2009, p. 14-15). Ao suprimir o "s" e gravar “decolonial” está se fazendo uma distinção entre uma decolonialidade empenhada em "reverter o colonial” (“descolonial”) para "um caminho de luta contínua no qual podemos identificar, visibilizar e incentivar "lugares" de exterioridade e construções alternativas ("decolonial”) (WALSH, 2009, p. 14-15). Portanto, a ideia da decolonialidade transcende o processo histórico e revela a face obscura do projeto modernidade/colonialidade, "que permanece operando ainda nos dias de hoje em um padrão mundial de poder” (BALLESTRIN, 2013a). Enquanto a descolonização aponta para a superação do colonialismo associado às lutas anticoloniais que possibilitaram a independência política das antigas colônias, a decolonialidade "supõe um projeto mais profundo e uma tarefa urgente para o nosso presente de subversão do padrão de poder colonial” (RESENDE, 2014, p. 52-53).

Outra delimitação necessária consiste em situar a utilização do termo decolonial por um grupo específico composto por intelectuais latino-americanos e americanistas empenhados na tarefa da decolonização e que, a partir da década de 1990, deu origem ao Grupo Modernidade/Colonialidade/Decolonialidade (Grupo M/C/D). Fortemente marcado pela necessidade de decolonizar a epistemologia e o cânone ocidentais, o Grupo M/C/D rompe parcialmente com a teorização dos grupos de Estudos Subalternos e avança para a crítica decolonial que denuncia o eurocentrismo por parte dos saberes silenciados e subalternizados. O mundo do colonizado é assumido à luz da dominação do colonizador de modo que a cultura daquele que foi subalternizado emerja como forma de denúncia e, ao mesmo tempo, apresente a sua riqueza injustamente ocultada e roubada, muitas vezes.

A utilização da palavra "decolonial” aparece nas reflexões do Grupo M/C/D como um instrumento político, epistemológico e social de construção de instituições e relações sociais marcadas pela superação das lógicas opressoras que almejam uma geopolítica mundial perversa e desigual. Além disso, o conceito “decolonial” insere-se 
em outra genealogia de pensamento, sendo o constitutivo diferencial desse grupo. Conforme Mignolo, sem a desobediência epistêmica “não será possível o desencadeamento epistêmico e, portanto, permaneceremos no domínio da oposição interna aos conceitos modernos e eurocentrados, enraizados nas categorias de conceitos gregos e latinos e nas experiências e subjetividades formadas dessas bases, tanto teológicas quanto seculares" (MIGNOLO, 2008, p. 288). Decolonial "significa pensar a partir da exterioridade e em posição epistêmica subalterna vis-à-vis à hegemonia epistêmica que cria, constrói, erige um exterior a fim de assegurar sua interioridade" (MIGNOLO, 2008, p. 304). A tarefa decolonial consiste em pensar a partir de outras línguas, de outra gramática, e categorias de pensamento que estão para além dos pensamentos ocidentais dominadores. O exercício do "aprender a desaprender, e aprender a reaprender" (MIGNOLO, 2008, p. 305) é constante nesse trabalho.

Nos anos 2000, muitos estudiosos se associaram ao Grupo M/C/D. Os encontros que vieram daí possibilitaram um intercâmbio fecundo de ideias em torno da decolonização. Pensamentos próprios como o de Enrique Dussel e a sua Filosofia da Libertação, a Teoria da Dependência de Aníbal Quijano e a Teoria do SistemaMundo de Immanuel Wallerstein, que desde a década de 1970 já chamavam a atenção para a necessidade de libertação das amarras epistêmicas coloniais, passam a ser incorporados pelo Grupo como fundamentos das teorias decoloniais. Com o tempo o Grupo vai criando identidade graças à troca constante de pensamentos e "contribuindo para a renovação analítica e utópica das ciências sociais latinoamericanas do século XXI” (BALLESTRIN, 2013b, p. 99). De uma genealogia imprecisa, o Grupo M/C/D é fruto de um intenso caldo teórico proveniente de várias frentes preocupadas com o processo de subalternização de povos e culturas e com o objetivo de fazer conhecidos os saberes que foram silenciados. Segundo Arturo Escobar, o Grupo M/C/D

Encontrou inspiração em um amplo número de fontes, desde as teorias críticas europeias e norte-americanas da modernidade até o grupo sul-asiático de estudos subalternos, a teoria feminista chicana, a teoria pós-colonial e a filosofia africana; assim mesmo, muitos de seus membros operaram em uma perspectiva modificada de sistema-mundo. Sua principal força orientadora, no entanto, é uma reflexão continuada sobre a realidade cultural e política latino-americana, incluindo o conhecimento subalternizado dos grupos explorados e oprimidos (ESCOBAR apud BALLESTRIN, 2013b, p. 99). 
Em linhas gerais, alguns elementos norteadores do pensamento decolonial proposto pelo Grupo M/C/D são:

\subsection{A colonialidade do poder, do saber e do ser}

O Grupo M/C/D é marcado profundamente pelo pensamento do sociólogo peruano Aníbal Quijano. O próprio nome do Grupo é uma apropriação da ideia do sociólogo peruano de que não existe modernidade sem colonialidade. Daí a utilização da barra inclinada (/) para realçar o valor disjuntivo entre os termos, ou seja, para separar elementos que representem alternativas. No caso utilizado, a conhecida "modernidade", aparentemente positiva, esconde uma face oculta: a colonialidade. A sua lógica opera em quatro domínios: econômico, político, social e epistêmico. Assim a modernidade oculta processos que reforçam o controle da economia, da natureza e dos recursos naturais, do gênero e da sexualidade, da subjetividade e do conhecimento e, inclusive, o conhecimento teológico.

A “colonialidade do poder" é uma categoria desenvolvida originalmente por Quijano, em 1989, e amplamente utilizada pelo Grupo M/C/D. A ideia foi difundida com a publicação do artigo Colonialidad y modernidad-racionalidad. Neste texto, Quijano faz críticas ao pressuposto fundamental do paradigma europeu de conhecimento racional e a sua aplicação nas relações de colonização. O conhecimento como produto da relação sujeito-objeto "nega a intersubjetividade e a totalidade como sedes de produção de todo conhecimento" (QUIJANO, 2016, p. 64) por causa do caráter falseador inerente ao sujeito, ser isolado da realidade, e objeto, "coisa" projetada pelo sujeito. Além disso, tal referência modelar "foi parte de uma estrutura de poder que implicava na dominação colonial europeia sobre o resto do mundo. Esse paradigma expressou, em um sentido demonstrável, a colonialidade dessa estrutura de poder" (QUIJANO, 2016, p. 65).

Tendo conhecimento do processo de colonização, o próximo passo assinalado por Quijano é a decolonização epistemológica, quer dizer, a busca por uma nova racionalidade livre da pretensão de uma cosmovisão específica de uma etnia particular que almeja se impor como única racionalidade universal. Diz Quijano: 
A libertação das relações interculturais da prisão da colonialidade implica também na liberdade de todas as pessoas, de optarindividual e coletivamente em tais relacionamentos; uma liberdade de opção entre as diversas orientações culturais. E, sobretudo, a liberdade para produzir, criticar, trocar e intercambiar cultura e sociedade. Em parte, finalmente, do processo de libertação social de todo poder organizado que alimenta a desigualdade, a discriminação, a exploração e a dominação (QUIJANO, 2016, p. 70).

As relações de colonialidade nas esferas econômicas, sociais e políticas não acabaram com o fim do colonialismo. As formas coloniais de dominação continuam em evidência mesmo após o término das administrações coloniais. O conceito “colonialidade" não se restringe ao poder, mas está presente nos âmbitos do saber e do ser também. A matriz colonial do poder é uma estrutura complexa com níveis entrelaçados potencializando o lado obscuro da modernidade. Para Nelson Maldonado-Torres, a colonialidade do ser nasceu em conversações sobre as implicações da colonialidade do poder, em diferentes áreas da sociedade. A colonialidade do poder aponta para a inter-relação entre as formas modernas de exploração e dominação correlacionadas com a do saber, ou seja, com a tarefa de produção e reprodução do conhecimento do pensamento colonial (MALDONATOTORRES, p. 130).

Para Quijano, a questão da classificação social é um instrumento importante para a empresa colonial. Raça, gênero e trabalho foram as três linhas principais de classificação que constituíram a formação do capitalismo mundial colonial/moderno no século XVI. E é nessas três instâncias que as relações de exploração/dominação/conflito estão ordenadas. "A classificação racial/étnica da população do mundo como pedra angular do dito padrão de poder opera em cada um dos planos, âmbitos e dimensões materiais e subjetivas, da existência social cotidiana e da escala social. Origina-se e mundializa-se a partir da América” (QUIJANO, 2014, p. 285).

Segundo Quijano: 
Na América, a ideia de raça foi uma maneira de outorgar legitimidade às relações de dominação impostas pela conquista. A posterior constituição da Europa como nova identidade depois da América e a expansão do colonialismo europeu ao resto do mundo conduziram à elaboração da perspectiva eurocêntrica do conhecimento e com ela à elaboração teórica da ideia de raça como naturalização dessas relações coloniais de dominação entre europeus e não-europeus. Historicamente, isso significou uma nova maneira de legitimar as já antigas ideias e práticas de relações de superioridade/inferioridade entre dominantes e dominados. Desde então demonstrou ser o mais eficaz e durável instrumento de dominação social universal, pois dele passou a depender outro igualmente universal, no entanto mais antigo, o intersexual ou de gênero: os povos conquistados e dominados foram postos numa situação natural de inferioridade, e consequentementetambém seus traços fenotípicos, bem como suas descobertas mentais e culturais. Desse modo, raça converteu-se no primeiro critério fundamental para a distribuição da população mundial nos níveis, lugares e papéis na estrutura de poder da nova sociedade. Em outras palavras, no modo básico de classificação social universal da população mundial (QUIJANO, 2005, p. 118).

A constituição da América e do capitalismo colonial/moderno e eurocentrado passou a ser o novo padrão de poder mundial. A classificação social serviu como elemento fundamental para o reforço desse empreendimento colonial. A ideia de "raça", como naturalização das novas relações de poder impostas pelo colonizador, destruiu as subjetividades dos povos colonizados, classificou-os como "inferiores" e, por fim, levou-os ao extermínio.

Com a ideia de raça produzida na América, além da classificação indígena, surgiram também novas identidades sociais como, negros e mestiços, assim como, surgiu a denominação espanhola, portuguesa e europeia. As categorias utilizadas geograficamente como forma de identificar a origem do indivíduo passaram a ser uma característica determinante para a construção identitária dos novos grupos sociais. Com isso nasce o primeiro sistema de classificação social global da história: branco, índio, negro, mestiço e outros, vítimas da racialização, e uma nova terminologia geográfica do poder imposta ao restante do planeta. Outras instâncias de dominação foram se redefinindo e se configurando em torno da ideia de raça, como a de gênero e de religião, por exemplo. Assim, o perfil imposto e dominante sobre o colonizador era: homem, europeu, branco, heterossexual e cristão. Aqueles que estavam fora do padrão eram subjugados.

\subsection{O pensamento liminar}

A colonialidade do saber ou, segundo Walter Mignolo, "geopolítica do conhecimento", é um dos temas mais recorrentes dentro das discussões do Grupo 
M/C/D. A noção de violência epistêmica, elaborada por Michel Foucault na sua crítica à modernidade e na relação entre poder e conhecimento visando o controle social, não conseguiu captar o eurocentrismo e a sua face colonialista e nem o silêncio oriundo do "racismo epistêmico", segundo Maldonato-Torres (MALDONATOTORRES, 2004, p.29-56), ou a negação da “alteridade epistêmica”, conforme CastroGómez (CASTRO-GÓMEZ, 2005, p.87-95), ou ainda, para Boaventura de Sousa Santos (SANTOS, 1999), "epistemicídio". O eurocentrismo é uma lógica fundamental para a reprodução da colonialidade do saber, como mostra Quijano. “A elaboração intelectual do processo de modernidade produziu uma perspectiva de conhecimento e um modo de produzir conhecimento que demonstram o caráter do padrão mundial de poder: colonial/moderno, capitalista e eurocentrado" (QUIJANO, 2016, p.60-61).

Mignolo aponta para a emergência de novos lugares de enunciação, uma "gnose liminar" que é expressão de uma razão subalterna lutando para afirmação dos saberes historicamente subalternizados. Para ele, estamos vivendo a emergência de um “outro pensamento”, um pensamento entre lugares que aponta para uma razão pós-ocidental. Essa gnose ou pensamento liminar é uma reflexão crítica sobre a produção do conhecimento e implica na sua redistribuição geopolítica até então pautada na colonização epistêmica e na subalternização de todas as formas de saberes, povos e culturas que não estivessem pautadas nos cânones da ciência eurocêntrica. Segundo Mignolo:

O potencial epistemológico do pensamento liminar, de um outro pensamento, tem a possibilidade de superar a limitação do pensamento territorial (isto é, a epistemologia monotópica da modernidade), cuja vitória foi possibilitada por seu poder de subalternizar o conhecimento localizado fora dos parâmetros das concepções modernas de razão e racionalidade. Uma dupla crítica libera conhecimentos que foram subalternizados, e a liberação desses conhecimentos possibilita "um outro pensamento" (MIGNOLO, 2003, p. 103).

O deslocamento do lócus de enunciação dos centros do sistema modernocolonial para suas margens, para as fronteiras das diferentes histórias locais não significa negar a importância da ciência e das formas de saberes ocidentais hegemônicas. A configuração-chave do pensamento liminar é pensar a partir de conceitos dicotômicos ao invés de organizar o mundo em dicotomias. Não se trata também de um relativismo cultural e epistêmico. Esses projetos não são universais e abstratos, mas circunscritos nos limites das diferenças coloniais específicas na 
formação do sistema-mundo moderno colonial. Nesse sentido, parece-nos pertinente o posicionamento epistêmico de Mignolo na apropriação da categoria de "mais além" de Anthony Giddens como uma postura interepistêmica (MIGNOLO, 2007, p. 138160).

Uma reflexão pós-colonial que não passa pela desobediência epistêmica não é capaz de constituir um novo sujeito epistemológico que pensa a partir das margens do conhecimento estabelecido. A razão subalterna revela uma mudança de terreno em relação à própria fundação do pensamento moderno como prática cognitiva, política e teórica. O projeto decolonial lida com a epistemologia de fronteira e uma linha metodológica em que duas realidades se encontram. "Nessa interseção uma dupla crítica torna-se um pensamento liminar, já que criticar a ambos implica em pensar a partir de ambas as tradições, e, ao mesmo tempo, de nenhuma delas" (MIGNOLO, 2003, p. 102). Esse pensamento liminar, com essa dupla crítica, é condição de possibilidade para um pensamento localizado na fronteira da colonialidade do poder no sistema mundial moderno. "Como tal, estabelece alianças com a crítica interna, a crítica monolítica da modernidade na perspectiva da própria modernidade, ao mesmo tempo em que marca a diferença irredutível do pensamento liminar como crítica a partir da diferença colonial” (MIGNOLO, 2003, p. 128).

Reconhecida a colonialidade, o próximo passo indispensável é a abertura, a desobediência, a vigilância e suspeição epistemológicas ou, segundo Quijano, "desprendimiento" e que Mignolo batiza de "de-linking”, uma tradução para o inglês do termo utilizado em espanhol e que atribuiu a seu projeto de mudança epistemológica. Foi no campo epistemológico que a retórica da modernidade ganhou força por produzir e reproduzir discursos e narrativas que justificam a colonialidade. “O paradigma decolonial luta por fomentar a divulgação de outra interpretação que põe em evidência uma visão silenciada dos acontecimentos e também mostra os limites de uma ideologia imperial que se apresenta como a verdadeira e única interpretação" (MIGNOLO, 2007, p. 57).

Mignolo defende a decolonização epistêmica, isto é, ela se desvincula dos fundamentos genuínos dos conceitos ocidentais e da acumulação de conhecimento. $\mathrm{O}$ desvinculamento epistêmico não significa abandono ou ignorância do que já foi institucionalizado por todo o planeta, mas um aprender a desaprender, learning to unlearn: 
Decolonização (da mente) deve revelar o totalitarismo da cumplicidade da retórica da modernidade e a lógica da colonialidade, a fim de abrir espaço para a possibilidade [...] de "outro mundo", em que muitos mundos coexistirão (MIGNOLO, 2007, p. 469).

A decolonização pressupõe o pensamento fronteiriço, border thinking, como lugar entre a diversidade das histórias subalternas e suas correspondentes subjetividades, isto é, o pensamento deve vir das margens. Os projetos decoloniais são pluriversais e não universais como os projetos da modernidade ocidental. Apoiado no conceito de transmodernidade cunhado por Enrique Dussel, Mignolo afirma que a crítica deve vir não só de fora, mas da exterioridade: "onde a diferença entre o 'espaço da experiência' e entre 'o horizonte da expectativa' torna-se aparente" (MIGNOLO, 2007, p. 494).

A gnose liminar, enquanto conhecimento, é produzida na interseção dos colonialismos modernos e do conhecimento produzido na perspectiva das modernidades coloniais. É uma forma de conhecimento construído nos espaços liminares, nas fronteiras da diferença colonial, uma poderosa e emergente gnoseologia que, na perspectiva do subalterno, está deslocando e absorvendo as formas hegemônicas do conhecimento. Não se trata de sincretismo e nem de hibridismo, mas de uma maneira de ser e de existir de todos aqueles que habitam a fronteira. Para Mignolo:

Quem habita a fronteira do lado da colonialidade "sente", cedo ou tarde, a diferença colonial. A questão é o que fazemos uma vez que estamos conscientes? Há três caminhos possíveis: tentamos nos assimilar, e boa sorte na assimilação; nos adaptamos o melhor que podemos, pois temos que viver; ou, a terceira, nos adaptamos e começamos a construir projetos que apontam para outras formas de vida. Neste momento a consciência e o ser de fronteira transformam-se no pensamento fronteiriço em ação, colocamos a experiência e o pensamento em ação. Alguns chamam isto de pensamento (ou posicionamento) crítico fronteiriço. O “crítico" está sobrando porque o pensamento fronteiriço em ação é necessariamente crítico e decolonial e distingue-se da teoria crítica da Escola de Frankfurt (MIGNOLO, 2013).

A teoria da decolonialidade é tanto um discurso crítico que traz para o primeiro plano o lado colonial do sistema mundial moderno e a colonialidade do poder embutida na própria modernidade, quanto um discurso que altera a proporção entre os locais geohistóricos e a produção de conhecimentos. A relação entre a localização geográfica e a epistêmica é estabelecida pela diferença colonial e pela 
colonialidade do poder. Tal movimento demanda um fazer decolonial, isto é, um giro com a pretensão de substituir a geopolítica de Estado de conhecimento de seu fundamento na história imperial do ocidente dos últimos cinco séculos, pela geopolítica de Estado de pessoas, línguas, religiões, conceitos políticos e econômicos, subjetividades e outros, que foram negados. Esse comprometimento pressupõe desvelar a lógica da colonialidade e a reprodução da matriz colonial do poder para desconectar-se dos efeitos totalitários das subjetividades e categorias do pensamento ocidental hegemônico.

\subsection{O giro decolonial}

O termo "giro decolonial" foi desenvolvido pelo filósofo porto-riquenho Nelson Maldonado-Torres, assinalando para um "movimento de resistência teórico e prático, político e epistemológico, à lógica da modernidade/colonialidade” (BALLESTRIN, 2013, p. 105). O termo remete a um giro epistemológico capaz de repensar a teoria da dependência numa crítica à modernidade e ao eurocentrismo, fazendo da dialética o seu método e uma nova visão da história. Assim, a decolonialidade surge como um terceiro elemento do processo modernidade/colonialidade/decolonialidade. A categoria "giro decolonial" tem um amplo campo de atuação que é fruto do refinamento teórico do Grupo M/C/D:

\footnotetext{
Vai desde a crítica da chamada colonialidade do saber, a transformação afirm ativa de diferentes espaços, subjetividades individuais e coletivas, instituições e modos de ser que geram e perpetuam relações de dominação. A colonialidadeé um elemento complementar da descolonização: enquanto esta última remete a transformação das estr uturas econômicas e políticas, aquela implica uma crítica às formas de produção do saber, aos processos de subjetivação e às relações so ciais que unem processos de subalternização (MOJICA, 2007, p. 239).
}

O giro decolonial implica na produção de sentido que remete à experiência gerada pela diferença colonial. A epistemologia fronteiriça baseada nessa diferença, na subjetividade da ferida colonial permite a passagem do paradigma hegemônico para referenciais teóricos outros de coexistência. "O paradigma decolonial luta por fomentar a divulgação de outra interpretação que põe em evidência uma visão silenciada dos acontecimentos" e, ao mesmo tempo, revela "os limites de uma ideologia imperial que se apresenta como a verdadeira e única interpretação" 
(MIGNOLO, 2007, p. 57). O movimento circulatório decolonial desvela a experiência subalterna do mundo permitindo a articulação de diferentes lugares, saberes e subjetividades que foram silenciados pela colonização. Mais do que uma opção teórica, o giro decolonial se impõe como uma necessidade ética e política capaz de se desprender da colonização do poder, do ser e do saber.

O pensamento fronteiriço decolonial emerge de outras fontes históricas que foram subalternizadas pelas histórias imperiais parciais, monotópicas e territoriais. Ele tem a "possibilidade de superar a limitação do pensamento territorial, cuja vitória foi possibilitada por seu poder de subalternizar o conhecimento localizado fora dos parâmetros das concepções modernas de razão e racionalidade” (MIGNOLO, 2003, p. 103). O pensamento decolonial recorre a outras narrativas. Por exemplo, os relatos do cronista Guaman Poma de Ayala, no século XIV, e o escravo liberto Ottobah Cugoano do século XVIII, são tratados políticos elaborados a partir da ferida colonial e denunciam a corrupção social da época. A genealogia do pensamento decolonial passa pelo acolhimento da fala dos que foram negados pela "história oficial" do colonizador. Segundo Mignolo:

\begin{abstract}
Colonialidade e decolonialidade introduzem uma fratura entre a pós-modernidade e a póscolonialidade como projetos no meio do caminho entre o pensamento pós-moderno francês de Michel Foucault, Jacques Lacan e Jacques Derrida e quem é reconhecido como a base do cânone pós-colonial: Edward Said, Gay atri Spivak e Hommi Bhabba. A decolonialidade - em contrapartida - arranca de outras fontes. Desde a marca decolonial implícita na Nueva Crónica y Buen Gobierno de Guaman Poma de Ayala; no tratado político de Ottobah Cugoano; no ativismo e crítica decolonial de Mahatma Ghandi; na fratura do Marxismo em seu encontro com o legado colonial nos Andes, no trabalho de José Carlos Mariátegui; na política radical, o giro epistemológico de Amilcar Cabral, Aimé Césaire, Frantz Fanon, Rigoberta Menchú, Gloria Anzaldúa, entre outros (MIGNOLO, 2010, p. 14).
\end{abstract}

O pensamento decolonial não se limita a indivíduos, mas é uma circulação planetária presente em movimentos sociais como o Fórum Social Mundial, o Fórum Social das Américas, o Movimento dos Sem Terra, aqui no Brasil, em movimentos sociais indígenas, afro, LGBT, movimentos em prol da terra, água, planeta e tantos outros. A lógica decolonial está presente em ações que colocam sob suspeita os trâmites coloniais nas esferas do poder - econômico e político, e do conhecimento e do ser - gênero, sexualidade, subjetividade e conhecimento. Além disso, o pensamento decolonial é fronteiriço, quer dizer, "do ponto de vista lógico, um lócus 
dicotômico de enunciação, e, historicamente, situa-se nas fronteiras, interiores e exteriores, do sistema mundo colonial moderno" (MIGNOLO, 2003, p. 126).

O pensamento fronteiriço abriga as experiências subalternas como exercício de autocompreensão sobre as políticas públicas, que criam condições para transformar, e estigmatizar, as relações de subalternidade. Dussel utiliza o termo "transmodernidade", além do eurocentrismo, além do ocidentalismo, para sustentar a posição de um sistema mundo pensado a partir da periferia e desamarrado das imposições ideológicas e políticas colonizadoras. Segundo ele:

[A transmodernidade] significa a erupção, a partir do "nada", desde a exterioridade alternativa do sempre diferente, de culturas universais em processo de desenvolvimento, que assumem os desafios da modernidade, e até mesmo a pós-modernidade europeia e norteamericana, mas respondem desde outro lugar, outra localidade. Desde o lugar de suas próprias experiências culturais, distintas da europeia e norte-americana, e, portanto, capazes de responder com soluções absolutamente impossíveis para uma só cultura moderna (DUSSEL, 2018, p. 18).

Mignolo coloca a questão da seguinte forma:

O pensamento liminar se estrutura numa dupla consciência, uma dupla crítica atuando no imaginário do sistema mundial colonial/moderno e da modernidade/colonialidade. Como tal, estabelece alianças com a crítica interna, a crítica monotópica da modernidade na perspectiva da própria modernidade, ao mesmo tempo em que marca a diferença irredutível do pensamento liminar como crítica a partir da diferença colonial (MIGNOLO, 2003, p. 128129).

A possibilidade de teorizar a partir da margem, como local geográfico e epistemológico, contribui para que se transcenda o eurocentrismo, reconhecendo as realizações e revelando as condições da geopolítica do conhecimento no mundo moderno/colonial. O pensamento de fronteira aponta para uma epistemologia alternativa ao pensamento hegemônico ocidental. A fronteira é vista como zonas fluídas capazes de propiciar relações de continuidade. A diferença colonial está em todas as partes, na periferia do centro e no centro da periferia. Esse pensamento de fronteira que vai para além da modernidade cria, segundo Santos, "zonas de contato":

Zonas em que ideias, conhecimento, formas de poder, universos simbólicos e modos de agir rivais se encontram em condições desiguais e interagem de múltiplas formas (resistência, rejeição, assimilação, imitação, tradução, subversão etc.) de modo a dar origem a constelações culturais híbridas, nas quais a desigualdade das trocas pode ser reforça da ou reduzida. A complexidade é intrínseca à própria definição de zona de contato (SANTOS, 2014, p. 81). 
Por isso, no giro decolonial a "interculturalidade deve ser entendida no contexto do pensamento e dos projetos decoloniais” (MIGNOLO, 2008, p. 316). E mais: “A inter-cultura, na verdade, significa inter-epistemologia, um diálogo intenso que é o diálogo do futuro entre cosmologia não ocidental e ocidental” (MIGNOLO, 2008, p. 316).

\section{TEOLOGIA DECOLONIAL}

A teologia não é um saber autônomo. Ela dialoga constantemente com outros saberes na busca por um fazer teologal contextualizado e pertinente. Dentre muitas possibilidades de diálogo, as ciências sociais têm sido uma parceira importante para a tarefa pública da teologia. A teologia da libertação, por exemplo, tem feito das ciências sociais uma mediação sócio-analítica (MSA) fundamental entre a teologia e a sociedade. A MSA nos faz aceder ao texto social e discernir a situação de opressão/colonização que afetam o empobrecido, que é o interlocutor e o destinatário principal da teologia em perspectiva decolonial. O objetivo da MSA vai para além da reflexão e foca na análise que está por trás do fenômeno social, quer dizer, para o "lado positivo e experimental das questões e não para o seu lado abstrato; para o aspecto prático, e não para as discussões puramente teóricas e, muitas vezes, inconcludentes" (BOFF, 1998, p. 380).

É preciso dizer que nem todas as ciências sociais servem de MSA à teologia. Há tantos estudos reducionistas sobre as atitudes humanas relacionadas com as estruturas sociais como aqueles que se apropriam de elementos quantitativos em hipótese e verificações que maquiam a realidade social e ocultam a verdadeira situação de opressão e injustiças sociais. Há que discernir o processo de evolução e involução das ciências sociais e o seu impacto sobre uma análise efetiva capaz de desideologizar a nossa mente. Nada, absolutamente nada, pode embaçar a nossa capacidade de "ver" com profundidade a situação humana. Como disse Teilhard de Chardin: "esforço para ver e fazer ver o que passa a ser e o que exige o Homem, quando inserimos, todo inteiro e até o fim, no quadro das aparências" (CHARDIN, 2006, p. 25). Já na teologia em perspectiva decolonial, não se trata de ver o "homem" de que fala Teilhard, mas o empobrecido. 
João Batista Libanio afirma que para se resguardar da influência das ideologias sobre os lugares comuns e interpretações generalizadas, a MSA na teologia:

Apropria-se dos resultados teóricos interpretativos das ciências do social em relação à realidade humana histórica. Chama-se mediação porque mediatiza, isto é, faz a função de ponte teórica entre a realidade humana histórica e o conhecimento propriamente teológico, proporcionando a este uma elaboração científica da realidade humana histórica. É uma mediação analítica porque apreende os dados, não de maneira intuitiva e experiencial, mas pela via da análise, da distinção entre os elementos constitutivos do real e suas relações. Dizse sócio-analítica porque o real é estudado na sua condição de estrutura social, situado dentro da sociedade e sujeito às leis que regem o univ erso das formações sociais, quer sejam econômicas, políticas ou culturais (LIBANIO, 1987, p. 178).

Portanto, entre a busca de uma teologia contextual, libertadora e uma análise sociológica efetiva, a MSA assume um papel intermediário importante. Acolher as teorias sociais decoloniais e deixar a teologia ser provocada por elas possibilita dar a intelecção da fé novos horizontes de reflexão. Nesse jogo de interpretação, a relação entre a sociologia e as ações dos seres humanos em condições de modernidade/colonialidade/decolonialidade deve ser compreendida de forma dinâmica. "O conhecimento sociológico espirala dentro e fora do universo da vida social, reconstituindo tanto este universo como a si mesmo como uma parte integral deste processo". Assim, “os conceitos e descobertas sociológicas estão constitutivamente envolvidos no que a modernidade é", diz Anthony Giddens (GIDDENS, 1991, p. 25-26).

A teologia é provocada a se decolonizar para criticar a matriz cultural do poder colonial ampliando então o seu horizonte epistemológico para ver e agir de modo eficiente junto aos movimentos sociais que vêm reivindicando antigos e novos direitos negados. Daí a importância da MSA. As críticas feitas à modernidade/colonialidade abrem espaço para novos lugares de enunciação marcados pelo pensamento decolonial de sociedades que saíram de experiências de violência, servidão e dominação impostas pela colonização ocidental. A produção teórica decolonial possibilita outro olhar no campo teológico sensível às causas de grupos sociais marginalizados e silenciados.

Uma teologia que almeja ser decolonial necessita assumir um caminho que a liberte de toda forma e fôrma. Sugerimos três possibilidades. 


\subsection{A libertação da teologia}

No início de 1970, Juan Luis Segundo já falava sobre a libertação da teologia das amarras colonizadoras no seu famoso livro Libertação da Teologia. Esta libertação acontece quando a teologia se submete ao exercício libertador das suas ideias e métodos arcaicos próprios de uma intelecção da fé encerrada em sua torre de marfim. Remexer a base da teologia cristã, a partir das demandas do mundo contemporâneo e exigir que ela tenha uma palavra/ação efetiva, parece ser fundamental para uma teologia que anseia ser contextual. Para isto, Segundo propõe o exercício de libertação: primeiro, a suspeita ideológica; segundo, aplicação da suspeita a toda superestrutura e à teologia; terceiro, nova maneira de experimentar a realidade teológica levando a suspeita exegética e, quarto, uma nova hermenêutica. Quatro momentos importantes de um círculo hermenêutico para uma teologia liberta e libertadora que passa pela "suspeita sistemática de que tanto a teologia vivida, como sua expressão acadêmica, tem sido desviada para finalidades massivas, com sua correspondente distorção de conteúdos” (SEGUNDO, 1978, p. 252).

Segundo ainda diz que o momento de hoje é propício para analisar não tanto o conteúdo da teologia, mas o seu método. É o momento da epistemologia. Avaliar criticamente o método da teologia latino-americana e sua relação com a libertação. Para ele, "o único que pode manter indefinidamente o caráter libertador de uma teologia, não é seu conteúdo, mas o seu método” (SEGUNDO, 1978, p. 46). Uma teologia libertadora é uma intelecção da fé histórica, enriquecida com novas perguntas do presente e obrigada a uma nova interpretação de suas fontes. "Não existe teologia cristã, nem interpretação cristã do Evangelho sem opção política prévia” (SEGUNDO, 1978, p. 105). Por isso, a crítica ao academicismo como obstáculo à libertação humana:

[...] Que coloca como critérioúltimo uma neutralidade ideológica; que relativiza igualmente todas as pretensões de absoluto e todas as avaliações que umas ideias têm sobre as outras. Isto é o equivalente teológico de outro grande adversário ideológico da libertação: a pretendida morte das ideologias, ou o suicídio no altar da imparcialidade científica (SEGUNDO, 1978, p. 31).

A teologia cristã não é fruto de abstrações teóricas desconectadas da vida concreta, mas reflexões constituídas por pessoas historicamente situadas na 
concretude da realidade humana. O engajamento sócio-político é fundamental nessa empreitada. Portanto, não há como se manter de forma neutra diante das demandas políticas, sociais, culturais e outras. O silêncio não é uma postura apartidária. Aqueles que se silenciam diante da injustiça, da corrupção e de qualquer transgressão assumem o partido dos injustos, dos corruptos e dos transgressores.

A teologia genuína é essencialmente decolonizadora. Ela é crítica de si mesma:

[...] Só isso pode fazer dela um discurso não-ingênuo, consciente de si, em plena posse de seus instrumentos conceituais. Mas não apenas a esse aspecto, de caráter epistemológico, fazemos alusão ao falar da teologia como reflexão crítica. Referimonos também a uma atitude lúcida e crítica com relação aos condicionamentos econômicos e socioculturais da vida e da reflexão da comunidade cristã: não os considerar é enganar-se e enganar os outros (GUTIÉRREZ, 2000, p. 68).

A teologia encontra a fonte de seu conhecimento não só nas palavras da fé, mas também, e iluminada por elas, na prática da fé, que atualiza e encarna a Palavra no aqui e agora da vida concreta. Teologia que não leva em consideração a práxis, isto é, a capacidade de transformação da realidade humana, não empenha o seu papel libertador. Mais do que refletir, é preciso mudar. Teologia digna brota de um compromisso humano, pré-teológico, para mudar e melhorar o mundo. Ela é atitude crítica, iluminada pelas demandas do contexto. “A comunidade cristã professa uma fé que age pela caridade. Ela é - deve ser - caridade eficaz, ação, compromisso com o serviço. A teologia vem depois, é ato segundo" (GUTIÉRREZ, 200o, p. 68).

Cabe ao quefazer teológico se perguntar se está ou não comprometido com a prática libertadora; se está aberto ou não a decolonizar-se e transformar-se radicalmente, entendendo a necessidade e os mecanismos do ser, do fazer e do saber dos povos subalternos. Há uma constatação em alguns segmentos teológicos da atualidade de que "as exigências do contexto exigem uma transformação intercultural e inter-religiosa do fazer teológico em nossas cabeças, nosso hábito de trabalho, nosso modo de ensinar, nossas instituições” (FORNET-BETANCOURT, 2018, p. 55).

Libertar a teologia significa rever os seus fundamentos epistemológicos e verificar até que ponto eles são libertadores. Propostas teórico-empíricas do pensamento decolonial são aportes necessários para a intelecção da fé que pretende identificar o problema colonial imposto pela modernidade/colonialidade e questionar a lógica irracional e instrumental que daí advém. E não só isso. Do pensar para o 
fazer, a teologia decolonial se posiciona para a elaboração de um outro mundo possível em que os dispositivos de poder que mantêm a desigualdade, racialização e inferiorização de seres e saberes são superados por um projeto político, social, ético e epistêmico reconhecedor e legitimador das culturas subalternizadas.

\subsection{Teologia de fronteira}

A palavra "fronteira" tem um campo semântico interessante. Do sentido literal de limitação de área ao sentido figurado como contorno de espaços imaginários, o termo sugere a consciência de pelo menos dois ambientes separados e/ou ligados por uma linha fronteiriça. Mia Couto, no texto Repensar o pensamento, redesenhando fronteiras, ilustra a imagem física e abstrata suscitada pelo signo "fronteira" e o desafio para o pensamento:

Nosso pensamento, como toda a entidade viva, nasce para se vestir de fronteiras. Essa invenção é uma espécie de vício de arquitetura: não há infinito sem linha do horizonte. Desde a mais pequena célula aos organismos maiores, o desenho de toda a criatura pede uma capa, um invólucro separador. A verdade é esta: a vida tem fome de fronteiras. É assim que se passa e não haveria nada a lamentar. Porque essas fronteiras da natureza não servem apenas para fechar. Todas as membranas orgânicas são entidades vivas e permeáveis. São fronteiras feitas para, ao mesmo tempo, delimitar e negociar. O "dentro" e o "fora" trocam-se por turnos (COUTO, 2013, p. 196).

A fronteira é cheia de oportunidades e rica em novas possibilidades e desafios. O espaço fronteiriço desinstala o sujeito da zona de conforto e o provoca a mudança. $\mathrm{Na}$ fronteira, a ordem dá lugar à desordem e o simples cede espaço ao complexo. A fronteira dá ideia de totalidade dos espaços existentes nas linhas fronteiriças entre os saberes. Segundo Homi Bhabha, essas regiões são ideais para a construção de identidades porque favorecem a articulação de diferenças culturais num movimento de deslocamento e sobreposição de diferenças. Segundo ele, “esses 'entre-lugares' fornecem o terreno para a elaboração de estratégias de subjetivação - singular ou coletiva - que dão início a novos signos de identidade e postos inovadores de colaboração e contestação" (BHABHA, 2013, p. 20). A fronteira é ambiente de mobilidade, andança, no qual se permitem encontros com "o outro". 
A fronteira também é um lugar privilegiado para reflexões contestadoras de políticas hegemônicas. A fronteira como lugar da observação sociológica e do conhecimento revela os "conflitos e dificuldades próprios da constituição do humano no encontro de sociedades que vivem no seu limite e no limiar da história. É na fronteira que se pode observar melhor como as sociedades se formam, se desorganizam ou se reproduzem. É lá que melhor se veem quais são as concepções que asseguram esses processos e lhes dão sentido", afirma José de Sousa Martins (MARTINS, 2012, p. 10).

Interpelada pelas problematizações do pensamento decolonial, a fronteira passa a ser um lugar propício para o exercício da decolonialidade. Mais do que um lugar propício para estabelecer encontros, o espaço entre os diferentes se tornou também um ambiente contestador, isto é, as margens das culturas, das religiões, dos conhecimentos e de todos os âmbitos da vida são habitadas por minorias que foram subalternizadas, empobrecidas e silenciadas por políticas hegemônicas no empreendimento perverso da colonização. Na relação injusta entre o colonizador e o colonizado, a fronteira se tornou o recinto daquele que foi saqueado e explorado.

Como pensar e fazer teologia a partir dos espaços fronteiriços? Repensar a teologia a partir das margens do sistema moderno/colonial não significa negar o pensamento hegemônico ocidental, mas avançar para além dele. Um pensar a partir das fronteiras históricas locais. Mais do que as linhas onde se encontram e dividem a civilização e a barbárie, a margem é o local onde uma nova consciência emerge da repressão acarretada pela missão civilizadora. A teologia de fronteira, enquanto pensamento da margem, envolvida com o desengajamento decolonial dos povos originários de diferentes regiões do mundo, situados na periferia do mundo, reflete "a partir da exterioridade subjetiva e epistêmica fabricada no discurso de modernidade, rearticulando suas antigas cosmologias, artes, ciências e saberes" (MIGNOLO; SOUZA, 2015, p. 395).

"O pensamento fronteiriço é a singularidade epistêmica de qualquer projeto decolonial" (MIGNOLO, 2015, p. 175). O ser e o fazer, habitando as fronteiras, criam condições para ligar a epistemologia fronteiriça com a consciência dos empobrecidos, dos marginalizados ou dos subalternizados e, ao mesmo tempo, a desvinculação com um referencial teórico imperial e excludente. A teologia de fronteira não se empenha em se incluir como mais uma proposta teológica no rol das grandes teologias. Antes, a 
sua meta é habitar a margem e se nutrir do diálogo entre os diferentes com o cuidado de não cair na imposição das ideologias.

A sensibilidade com as diferenças é importante no processo de repensar a teologia. Pesa sobre a teologia cristã a imagem de um saber imposto, autoritário, insensível com os diferentes. A relação com o pobre, muitas vezes, é vista de forma piedosa no sentido paternalista tratando-o como uma criança inocente. É evidente que a crítica feita à teologia nem sempre se fundamenta. A relação da teologia da libertação com o pobre, por exemplo, não é essa, mas também, não podemos negar que, historicamente, a teologia se baseou na supressão tanto da sensibilidade como da localização geo-histórica do diferente. Por se julgar universal, exorcizou dos seus ambientes aqueles que não seguem o trâmite do que é tido como correto, verdadeiro, e assim reduziu o dessemelhante classificando-o como inferior.

O pensamento fronteiriço é a condição necessária para pensar de forma decolonial. A teologia que daí emerge aspira ser um pensamento independente. Para Mignolo, o pensamento independente necessita do espaço fronteiriço, "pela simples razão de que este não se pode lograr se mantiver dentro das categorias do pensamento e da experiência ocidentais; se mantiver na dialética e não habitar a analética. A analética é o lugar do pensamento fronteiriço” (MIGNOLO, 2015, p. 179). Apoiado na analética da filosofia da libertação de Dussel, Mignolo aponta para os limites da totalidade da dialética propondo a sua superação e a abertura para a novidade. O próprio Dussel esclarece este movimento:

O momento analético é por isso crítico e superação do método dialético negativo, não o nega, como a dialética não nega a ciência, simplesmente o assume, o completa, lhe dá seu justo e realvalor [...]. Éa afirmação da exterio ridade: não é somente negação da negação do sistema deste a afirmação da totalidade. É superação da totalidade, mas não só como atualidade do que está em potência no sistema. É a superação da totalidade desde a transcendentalidade interna ou da exterioridade, o que nunca esteve dentro. Afirmar a exterioridade é r ealizar o impossível para o sistema (não havia potência para isso), é realizar o novo, o imprevisível para a totalidade, o que surge a partir da liberdade incondicionada, revolucionária, inovadora (DUSSEL, 1986, p. 164-165).

A tentativa dusseliana de estabelecer um caminho analético aberto à exterioridade que possibilitasse a crítica das totalidades e uma práxis de libertação que não redundasse em novos totalitarismos interpela a um fazer teológico livre de totalitarismos e opressor. A necessidade de repensar ou recriar toda a teologia 
partindo da realidade opressiva do continente latino-americano passa a ser um desafio para uma intelecção da fé que acolhe a decolonialidade.

A teologia de fronteira está também relacionada à desobediência epistêmica com um desvincular dos fundamentos genuínos dos conceitos ocidentais e da acumulação de conhecimento rumo a uma nova episteme. Tal ruptura epistêmica implica em "modificar a regras do jogo e as relações de poder", isto é, "criar categorias de pensamento que não derivam da teoria política e da economia europeia e estadunidense, desprender-se e pensar dentro das fronteiras que habitam”, afirma Mignolo (MIGNOLO, 2015, p. 180). Com a crítica feita à colonialidade, a mudança epistemológica é indispensável para o projeto decolonial. A decolonialidade abre espaço para uma razão subalterna lutando para afirmação dos saberes historicamente subalternizados. O desvinculamento epistêmico demanda um aprender a desaprender para aprender a partir da margem. Movimento importante para a teologia que almeja permanecer num processo constante de reforma.

O desprendimento epistemológico coopera para um refazer teológico novo. Não se trata de desconsiderar todo o avanço histórico da teologia, mas avançar rumo a um teologizar comprometido como os novos personagens que surgem das margens. Questões indígenas, da sexualidade, dos direitos humanos, da ecologia, dos grupos LGBTI+, da migração e mobilidade humana são alguns exemplos de protagonismos deste novo cenário. Acolher os seus dilemas existenciais e os seus saberes dão à teologia o privilégio de se refazer na atualidade de modo libertador, decolonizador. Não se avança nesta direção sem uma ruptura epistemológica. "Toda mudança de decolonização política (não-racistas, não heterossexualmente patriarcal) deve suscitar uma desobediência política e epistêmica [...] A desobediência civil sem desobediência epistêmica permanecerá presa em jogos controlados pela teoria política e pela economia política eurocêntricas” (MIGNOLO, 2008, p. 287).

\subsection{Teologia e epistemologias do Sul}

“Epistemologias do Sul” é o nome dado à percepção do mundo epistemologicamente diverso. O valor dado a esta alteridade tem o seu lugar não só na academia, como na relação entre o mundo científico e a pluralidade de saberes populares que são externos à ciência. A lógica da diversidade de epistemologias revela 
o domínio de produção de conhecimento, o regime cultural e civilizacional, de um sistema neoliberal global que estende os seus tentáculos buscando o modo de ver e ser do sujeito no mundo. O "sul” agregado ao termo "epistemologias" é "concebido metaforicamente como um campo de desafios epistêmicos, que procuram reparar os danos e impactos historicamente causados pelo capitalismo na sua relação colonial com o mundo" (SANTOS; MENEZES, 2010, p. 19). Santos ainda diz que: "epistemologias do sul são o conjunto de intervenções epistemológicas que denunciam essa supressão, valorizam os saberes que resistiram com êxito e investigam as condições de um diálogo horizontal entre conhecimentos.” (SANTOS; MENEZES, 2010, p. 19).

Aprender que existe o Sul; aprender a ir para o Sul e aprender a partir do Sul e com o Sul são as três orientações básicas para pensar e fazer a partir das epistemologias do sul (SANTOS; MENEZES, 2010, p. 15). O giro decolonial será efetivo se "situarmos a nossa perspectiva epistemológica na experiência social do outro lado da linha, isto é, do sul global não-imperial, concebido como a metáfora do sofrimento humano sistêmico e injusto provocado pelo capitalismo global e pelo colonialismo" (SANTOS; MENEZES, 2010, p. 53). O confronto entre o pensamento hegemônico com a ideia de que o conhecimento é interconhecimento, isto é, o "reconhecimento da pluralidade de conhecimentos heterogêneos em interações sustentáveis e dinâmicas entre eles sem comprometer a sua autonomia” (SANTOS; MENEZES, 2010, p. 53) emerge o que Santos chama de "ecologia de saberes". Como um exercício epistemológico, a ecologia de saberes se baseia na "incompletude de qualquer tipo de conhecimento humano e destinado a identificar conhecimentos distintos e critérios de rigor e validade que operam credivelmente nas práticas sociais de modo a desenvolver interações criativas entre eles.” O seu objetivo é "ampliar a legitimidade intelectual e cultural das lutas pela dignidade humana”, conclui Santos (2014, p. 107).

Acolhendo a diversidade de epistemologias possíveis e reconhecendo-se diante do "outro", como espelho, a teologia se transforma e transformada pode cooperar para a transformação do mundo. Sem este exercício, dificilmente se faz teologia de forma decolonial. A crítica à epistemologia hegemônica, que se impõe por meio de um padrão - branco, masculino, europeu, heterossexual, cristão -, é necessária para uma teologia aberta a horizontes mais amplos. A imposição epistemológica não 
permite acolher a alteridade. "Epistemologias do Sul", ao contrário, não provoca imposições, mas possibilita abertura para um novo labor teológico. Juan José Tamayo aponta alguns horizontes para uma teologia decolonial: intercultural, interreligioso, hermenêutico, feminista, ecológico, ético-práxico, simbólico, anamnético, utópico, econômico-político (TAMAYO, 2017, p. 60-62). Tais horizontes possibilitam teologias emergentes a partir da realidade concreta de sujeitos subalternizados: teologia queer, teologia feminista, eco-teologia, teologia indígena, teologia dalit, teologia palestina da libertação e tantas outras teologias que dão voz aos marginalizados.

Para o teólogo negro da libertação, James Cone, teologia é "estudo racional do ser de Deus no mundo, à luz da situação existencial da comunidade oprimida, relacionando as forças da libertação com a essência do evangelho, que é Jesus Cristo" (CONE, 1973, p. 15). A razão deste labor teológico está em "traduzir em linguagem ordenada o significado da ação de Deus no mundo, em termos que levem a comunidade dos oprimidos a reconhecer como seu impulso interior em direção à libertação não só está em harmonia com o evangelho, mas que é o evangelho de Jesus Cristo" (CONE, 1973, p. 15). Associar decolonialidade à teologia significa empenharse na construção de outros lugares de enunciação como expressões de resistência diante da colonização do poder, dando voz às epistemologias do Sul global.

Conhecimento não se adquire somente na academia, a pluralidade de saberes populares - hierarquizados e classificados erroneamente -, também é conhecimento legítimo. Quem disse que isso ou aquilo é ou não é científico? As epistemologias do Sul, que emergem das margens da sociedade firmada no conhecimento produzido pelo centro, confrontam os saberes hegemônicos e dão voz à sapiência subalternizada. Como dizia o educador Rubem Alves: "as coisas que as redes da ciência não conseguem segurar são as coisas que a ciência não pode dizer" (ALVES, 2003, p. 103). A sapiência aponta os limites da ciência. As coisas tidas como "não científicas" escapam da nossa objetivação e se abrem para uma realidade do mistério.

A teologia decolonial abarca o dinamismo do conhecimento seja como ciência e como sapiência. A busca por tal dinâmica não se limita à simples relação polarizante entre um sujeito que pergunta pela essência e existência e um objeto inerte, passivo às indagações do sujeito. Antes, o enfoque, recai na superação do modelo tradicional (sujeito/objeto) para o modelo relacional (sujeito-objeto) em que 
os pressupostos, métodos e conclusões estão sujeitos à evolução de significado e compreensão (CUNHA, 2016, p. 111-126). Recorrendo ao mito poético da criação bíblica, Alves exorta sobre o valor do conhecimento para a vida:

Segundo o mito bíblico, o mais alto sonho de Deus é um jardim. Por isso, o Criador produziu o big-bang, só para, no final, plantar um paraíso. Eele nos criou para que tivéssemos prazer e alegria no jardim. Razão por que nossa vocação original é a de ser jardineiros. Tudo o que a gente faz, o trabalho, a ciência, a política, a arte, são meios para o grande fim que é o jardim. Saber por saber, saber que não sonha com o jardim, que só deseja virar tese ou artigo em revista internacional, é manifestação de loucura (ALVES, 2003, p. 45).

A teologia que emerge de um mundo epistemologicamente diverso tem na práxis (ação transformadora e libertadora) um retorno fundamental para o potencial do seu conhecimento. A vida das pessoas e das comunidades revela aspectos do mistério de Deus a que o teólogo e a teóloga devem atentar na elaboração de sua teologia. O teorizar só tem sentido quando nutrido por situações existenciais, caso contrário, são palavras vazias. Os tratados da fé ganham sentido quando são retroalimentados no exercício do confronto com a concretude da vida. Crenças corretas são oriundas de práticas corretas, o contrário também é verdadeiro.

\section{CONSIDERAÇÕES FINAIS}

O tema da decolonialidade é amplo, importante e complexo. Ele perpassa vários níveis da realidade aguçando a crítica contestadora dos modelos hegemônicos. Seja na cultura, na religião, no conhecimento ou outras instâncias, a teoria decolonial demanda um fazer também decolonial, isto é, um desprendimento epistemológico capaz de romper com a colonialidade do poder, do ser e do saber. A teologia não foge desta crítica e não escapa da decolonização. Decolonizá-la é um desafio a ser elaborado constantemente.

A teologia precisa ter coragem de intensificar o diálogo com o pensamento decolonial. Se a intelecção da fé busca ter o que dizer à contemporaneidade, ela não pode se colocar distante dela. Os movimentos de empoderamento da atualidade são contestadores de posturas hegemônicas e excludentes. Eles provocam a teologia a repensar o seu jeito de ser e fazer diante de novos horizontes de percepção da 
realidade das minorias que foram, historicamente, silenciadas, mas, que agora, ressurgem como vozes protestantes.

Espera-se que uma teologia de tarefa pública e pertinente seja capaz de repensar os seus próprios tratados e a sua prática a partir do mundo epistemologicamente diverso. Tal exercício permite contextualizar a sua natureza libertadora. Acolher os subalternizados e, com eles, resistir aos poderes hegemônicos é um serviço obrigatório de uma teologia cristã engajada na construção do reino de Deus no mundo. Na lógica do reino divino, o outro é o meu próximo. Amar a Deus e amar o próximo é a síntese da lei e dos profetas anunciada por Jesus Cristo (Mc 12,28-33; Mt 22,34-40; Lc 10,25-28). É o grande mandamento. A opção pelo empobrecido, marginalizado ou subalternizado implica em ser um com ele, fazer-se participante do seu sofrimento e da sua luta por dignidade. Isso é ser próximo.

\section{REFERÊNCIAS}

ALVES, Rubem. Entre a ciência e a sapiência: o dilema da educação. 10.ed. São Paulo: Loyola, 2003.

BALLESTRIN, Luciana. Para transcender a colonialidade. IHU Online. Edição 431, 4 nov. 2013a.

BALLESTRIN, Luciana. América Latina e o giro decolonial. Revista Brasileira de Ciência Política, n.11. Brasília, maio-agosto, 2013b.

BHABHA, Homi. O local da cultura. 2. ed. Belo Horizonte: Ed. UFMG, 2013.

BOFF, Clodovis. Teoria do método teológico. 3. ed. Petrópolis: Vozes, 1998.

CASTRO-GÓMEZ, Santiago. Ciências sociais, violência epistêmica e o problema da "invenção do outro". In: A colonialidade do saber: eurocentrismo e ciências sociais. Perspectivas latino-americanas. Buenos Aires: CLACSO, Consejo Latinoamericano de Ciencias Sociales, 2005.

CHARDIN, Teilhard de. O fenômeno humano. São Paulo: Cultrix, 2006.

CONE, James. Teología negra de la liberación. Ed. Carlos Lohlé: Buenos Aires, 1973 .

COUTO, Mia. Repensar o pensamento, redesenhando fronteiras. In: MACHADO, Cassiano Elek (Org.). Pensar a cultura. Porto Alegre: Arquipélago Editorial, 2013. 
CUNHA, Carlos. Paul Tillich e a teologia pública no Brasil: o contributo do método da correlação de Paul Tillich à epistemologia da teologia pública no Brasil no contexto do pensamento complexo e transdisciplinar. São Paulo: Garimpo Editorial, 2016.

CUNHA, Carlos. Provocações decoloniais à teologia cristã. São Paulo: Ed. Terceira Via, 2017.

DUSSEL, Enrique. Método para uma filosofia da libertação: superação analética da dialética hegeliana. São Paulo: Loyola, 1986.

DUSSEL, Enrique. Transmodernidad e interculturalidad: Interpretación desde la Filosofía de la Liberación. Disponível em:

<http://enriquedussel.com/txt/TRANSMODERNIDAD\%2oe\%2ointerculturalidad.p df>. Acesso em: 6 jul. 2018.

DUSSEL, Enrique. World-System and Transmodernity. Nepantla: Views from South (Duke, Durham), v. 3, Issue 2, 2002.

FORNET-BETANCOURT, Raúl. La interculturalidad a prueba. Disponível em: <http://www.uca.edu.sv/filosofia/admin/files/1210106845.pdf>. Acesso em: 19 jul. 2018.

GIDDENS, Anthony. As consequências da modernidade. São Paulo: Ed. Unesp, 1991.

GUTIÉRREZ, Gustavo. Teologia da libertação: perspectivas. São Paulo: Loyola, 2000.

LIBANIO, João Batista. Teologia da libertação: roteiro didático para um estudo. São Paulo: Loyola, 1987.

MALDONADO-TORRES, Nelson. The topology of being and the geopolitics of knowledge: modernity, empire and coloniality. In City, Vol. 8, nº 1, pp. 29-56. 2004.

MALDONADO-TORRES, Nelson. Sobre la colonialidad del ser: contribuciones al desarrollo de um concepto. Disponível em: <http://www.ram-wan.net/restrepo/decolonial/17-maldonadocolonialidad\%20del\%20ser.pdf>. Acesso em 29 de jun. de 2018.

MARTINS, José de Souza. Fronteira: a degradação do outro nos confins do humano. 2.ed. São Paulo: Contexto, 2012.

MIGNOLO, Walter. Decolonialidade como o caminho para a cooperação. IHU Online. Edição 431, nov. 2013. Disponível em: <http://www.ihuonline.unisinos.br/index.php>. Acesso em: 4 de jul. 2018. 
MIGNOLO, Walter. Delinking. The rethoric of modernity, the logic of coloniality and the grammar of de-coloniality. Cultural studies, v. 21, n. 2-3. Routledge. 2007.

MIGNOLO, Walter. Desobediência epistêmica: a opção descolonial e o significado de identidade em política. Cadernos de Letras da UFF - Dossiê: literatura, língua e identidade, $\mathrm{n}^{\mathrm{O}} 34,2008$.

MIGNOLO, Walter. Desobediencia epistémica: retórica de la modernidad, lógica de la colonialidad y gramática de la descolonialidad. Buenos Aires: Ediciones del Signio, 2010.

MIGNOLO, Walter. Habitar la frontera: sentir y pensar la descolonialidad. Barcelona: Edicions Bellaterra, 2015.

MIGNOLO, Walter. Histórias locais/Projetos globais: colonialidade, saberes subalternos e pensamento liminar. Belo Horizonte: Ed. UFMG, 2003.

MIGNOLO, Walter. La idea de América Latina. La herida colonial y la opción decolonial. Barcelona: Gedisa, 2007.

MIGNOLO, Walter; SOUZA, Júlio Roberto de. A modernidade é de fato universal? Reemergência, desocidentalização e opção decolonial. Revista Civitas, Porto Alegre, v.15, n. 3, jul.-set. 2015.

MIGNOLO, Walter; TLOSTANOVA, Madina. Learning to Unlearn: Decolonial Reflections from Eurasia and the Americas. Columbus: Ohio State University Press, 2012.

MOJICA, Dairo Andrés Sánchez. Reseña de "El giro decolonial: reflexiones para una diversidad epistémica más allá del capitalismo global” de Santiago Castro-Gómez y Ramón Grosfoguel (Eds.) Nómadas (Col), núm. 27, octubre, 2007.

QUIJANO, Aníbal. Colonialidad del poder y clasificación social. Buenos Aires: CLASO, 2014.

QUIJANO, Aníbal. Colonialidad y modernidad-racionalidad. In: PALERMO, Zulma; QUINTERO, Pablo (Coord.). Aníbal Quijano: textos de fundación. Buenos Aires: Editorial: Ediciones del Signo, 2016.

QUIJANO, Aníbal. Colonialidade do poder, Eurocentrismo e América Latina. Buenos Aires: CLASO, 2005.

QUIJANO, Aníbal. La americanidad como concepto o América en el mundo moderno-colonial In: PALERMO, Zulma; QUINTERO, Pablo (Coord.). Aníbal Quijano: textos de fundación. Buenos Aires: Editorial: Ediciones del Signo, 2016.

RESENDE, Ana Catarina Zema de. Direitos e Autonomia Indígena no Brasil (1960 - 2010): uma análise histórica à luz da teoria do sistema-mundo e do pensamento decolonial. (tese). Brasília: UnB, 2014. 
SANTOS, Boaventura de Sousa. Pela mão de Alice: o social e o político na pósmodernidade. 7.ed. Porto: Edições Afrontamento, 1999.

SANTOS, Boaventura de Sousa. Se Deus fosse um ativista dos direitos humanos. 2.ed. São Paulo: Cortez, 2014.

SANTOS, Boaventura de Sousa; MENESES, Maria Paula (Orgs.). Epistemologias do sul. São Paulo: Cortez, 2010.

SEGUNDO, Juan Luis. Libertação da teologia. São Paulo: Ed. Loyola, 1978.

TAMAYO, Juan José. Teologías del Sur: el giro descolonizador. Madrid: Editorial Trotta, 2017.

WALSH, Catherine. Interculturalidad, Estado, Sociedad: Luchas (de)coloniales de nuestra época. Universidad Andina Simón Bolivar, Ediciones Abya-Yala, Quito, 2009.

Recebido em: 28.09 .2018 Aprovado em: 16.12.2018 